\title{
Problems in making the decision to carry an extramarital pregnancy to term
}

\author{
Dimitar Gugutkov ${ }^{1}$, Svetoslav Garov ${ }^{2}$, Valchin Garov ${ }^{1}$
}

1. Multi-profile Hospital for Active Treatment "Doverie";

2. Faculty of Public Health, Medical University of Sofia;

\begin{abstract}
This paper analyzes the data from a survey carried out among 216 women who gave birth in three hospitals in the city of Sofia, Bulgaria.

The study of risk factors related to the family environment of single mothers is of extreme importance. They are directly correlated to the social aims and orientations of the mother's family and its microclimate.
\end{abstract}

Keywords: extramarital birth, single mothers, abortion.

\section{Introduction}

The refusal of fathers of children conceived out of wedlock to assume responsibility for their actions has a great impact on the decision-making process whether to interrupt an extramarital pregnancy or carry it to term. [5] This impact is enhanced by the fact that most fathers learn of the pregnancy in the very first months. [12] Most probably, this is a period when the unmarried pregnant woman hopes to settle her relationship with the child's father through marriage, which would also legitimize the expected child. $[9,11]$

Paul Amato examines the effects of family formation on children and evaluates whether current marriagepromotion programs in the USA are likely to meet children's needs. [1] He shows that children growing up with two continuously married parents are less likely to experience a wide range of cognitive, emotional, and social problems, not only during childhood but also in adulthood. 


\section{Aim}

The aim of the study is to investigate the problems encountered by future parents when making the decision to carry an extramarital pregnancy to term.

\section{Materials and methods}

The subject of the study is the extramarital births in the city of Sofia within the period 01.01.2016 30.06.2017. An empirical questionnaire survey was carried out among 108 single mothers of age and 108 married women who gave birth in First Specialized Hospital of Obstetrics and Gynecology "St. Sofia" EAD, Second Specialized Hospital of Obstetrics and Gynecology "Sheinovo", University Obstetrics and Gynecology Hospital "Maichin Dom". The new mothers were surveyed between 3rd and 5th day after giving birth, which reduced the disturbing impact of the childbirth process on their mental state. The study also used a documentary method. The primary information collected was analyzed using different mathematical and statistical methods. Proving factor dependencies requires establishing a statistically significant connection between the studied phenomenon - extramarital birth - and the supposed factor.

The analysis of factor dependencies requires measuring the strength of impact of the individual factors, thus determining their significance for the studied phenomenon. The ranking of individual factors by the strength of their dependency on the studied phenomenon is measured using Cramer's correlation coefficient for qualitative indicators.

\section{Results and discussion}

The study showed that $45.37 \%$ of the women who gave birth out of wedlock wanted the pregnancy and hoped to get married, and those who had decided to form an incomplete family are very few in number. This explains to a significant extent the high number of attempts for pregnancy interruption. While the relative share of married mothers who did not attempt to interrupt the pregnancy is $97.2 \%$, this share for women who gave birth outside marriage is only $68.5 \%$. [Figure1]

Figure 1. Attitude of the mothers and fathers towards the pregnancy (Cramer's coefficient $=0.637$ )

\section{Single mothers}
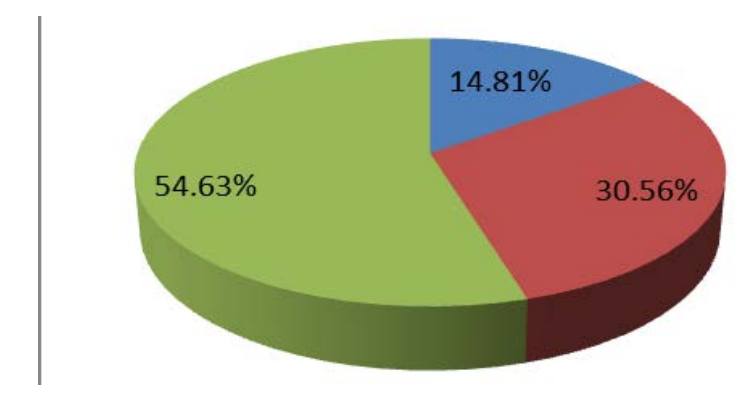

wanted by the mother and the father

- wanted only by the mother

unwanted by both 


\section{Married mothers}

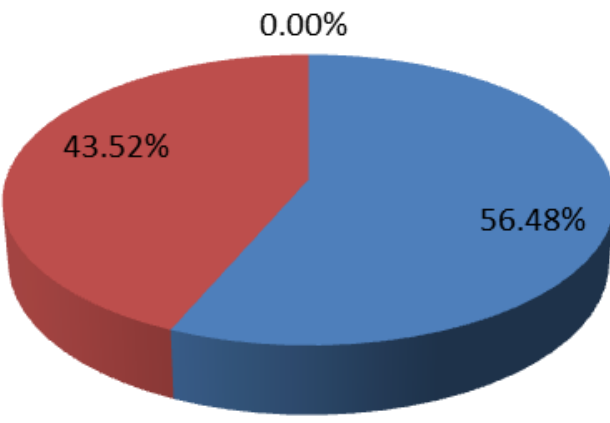

- wanted by the mother and the father

- wanted only by the mother

unwanted by both

The following responses to the question: "What is the immediate reason for single mothers carrying the pregnancy to term?" were received [Figure 2]:

- Hoping to get married - $21.3 \%$

- Promise of marriage - $11.1 \%$

- Fear of abortion - $13.0 \%$

- Medical contraindications - $6.5 \%$

- Color pregnancy - $7.4 \%$

- Desire to have a child - $38.9 \%$

- Impossible to find an acceptable solution - $1.8 \%$

Figure 2. Immediate reason for single mothers carrying the pregnancy to term

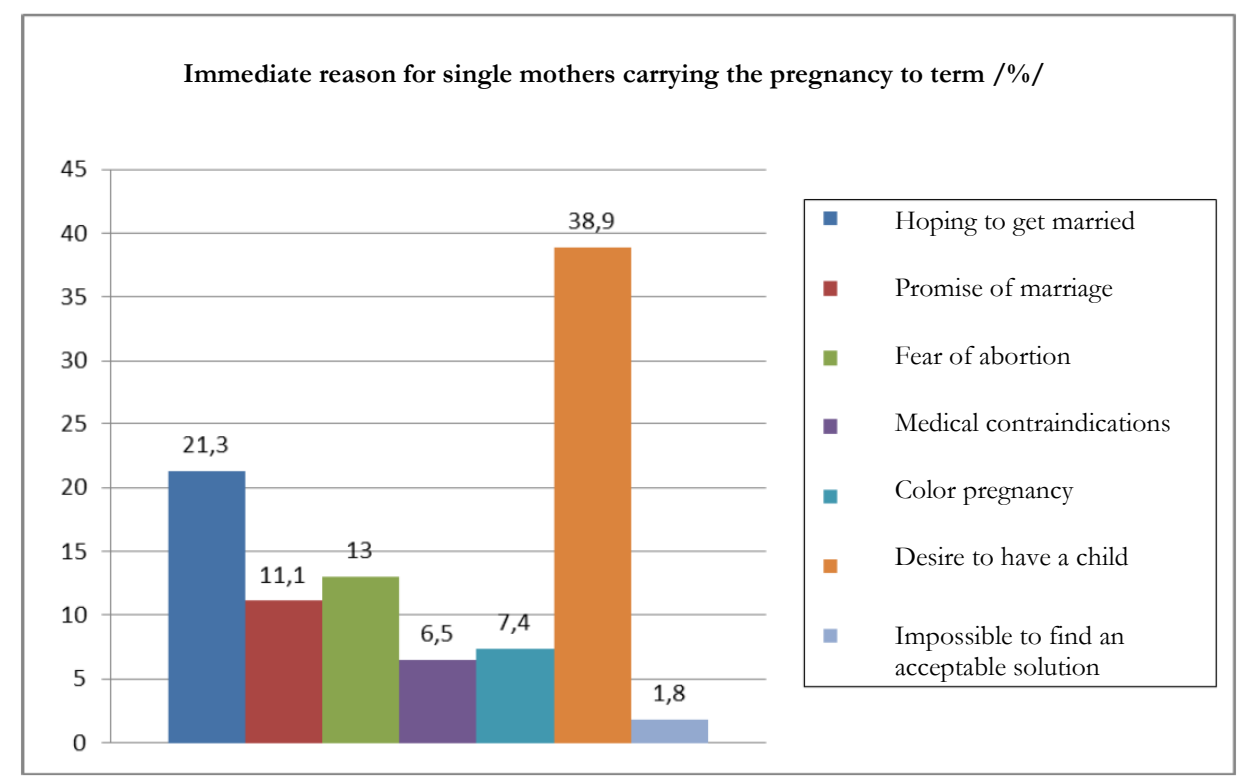


For the study, it was especially important to clarify to what extent the modern Bulgarian woman is independent and prepared to assume the responsibilities of her own reproductive behavior and decision to give birth outside marriage. [8]

The analysis of the single mothers' responses to the questions how they assess their parents' attitude towards them before and during the pregnancy, as well as whether one of the parents is dominant, showed deficiencies in the family as an educational environment. [4, 10] [Figure 3 and Figure 4]

Figure 3. Attitude of the parents before pregnancy

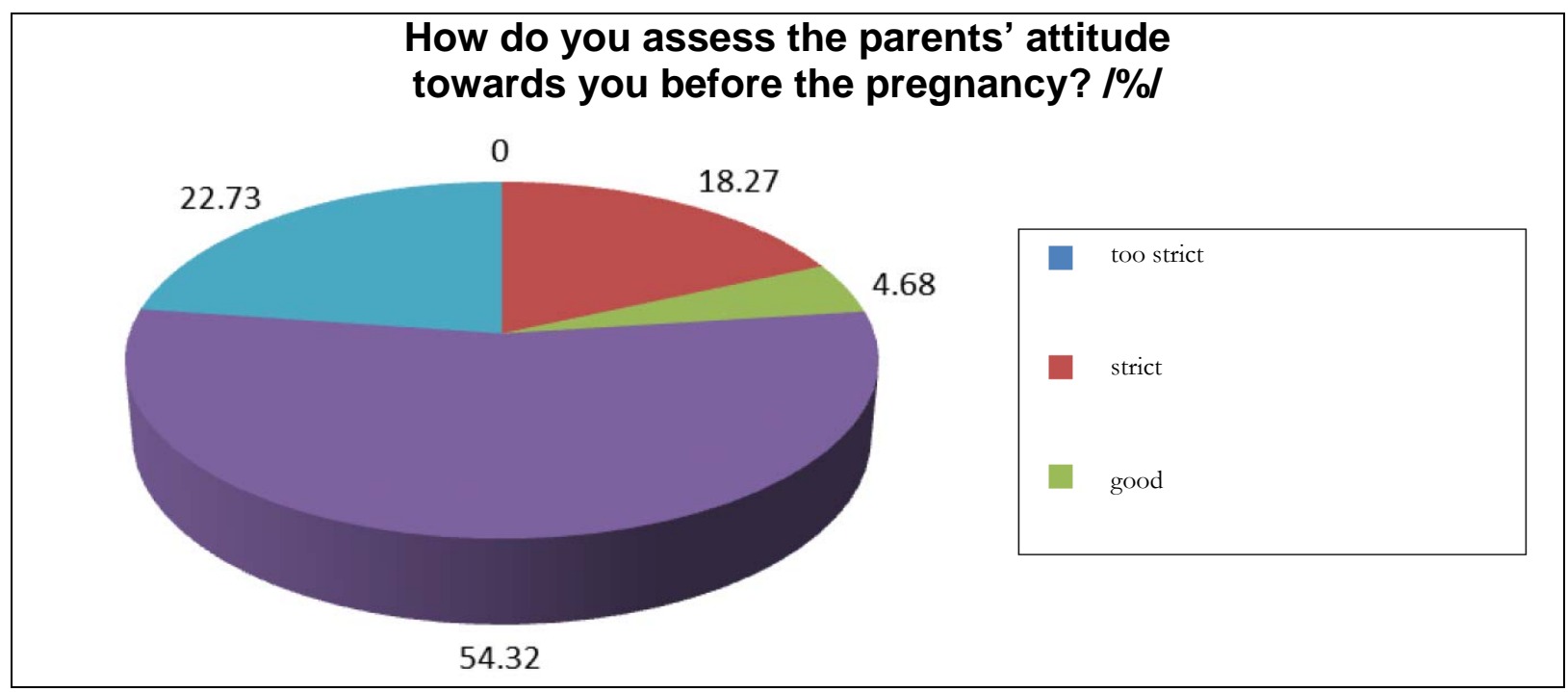

Figure 4. Dominant role of a parent in the family

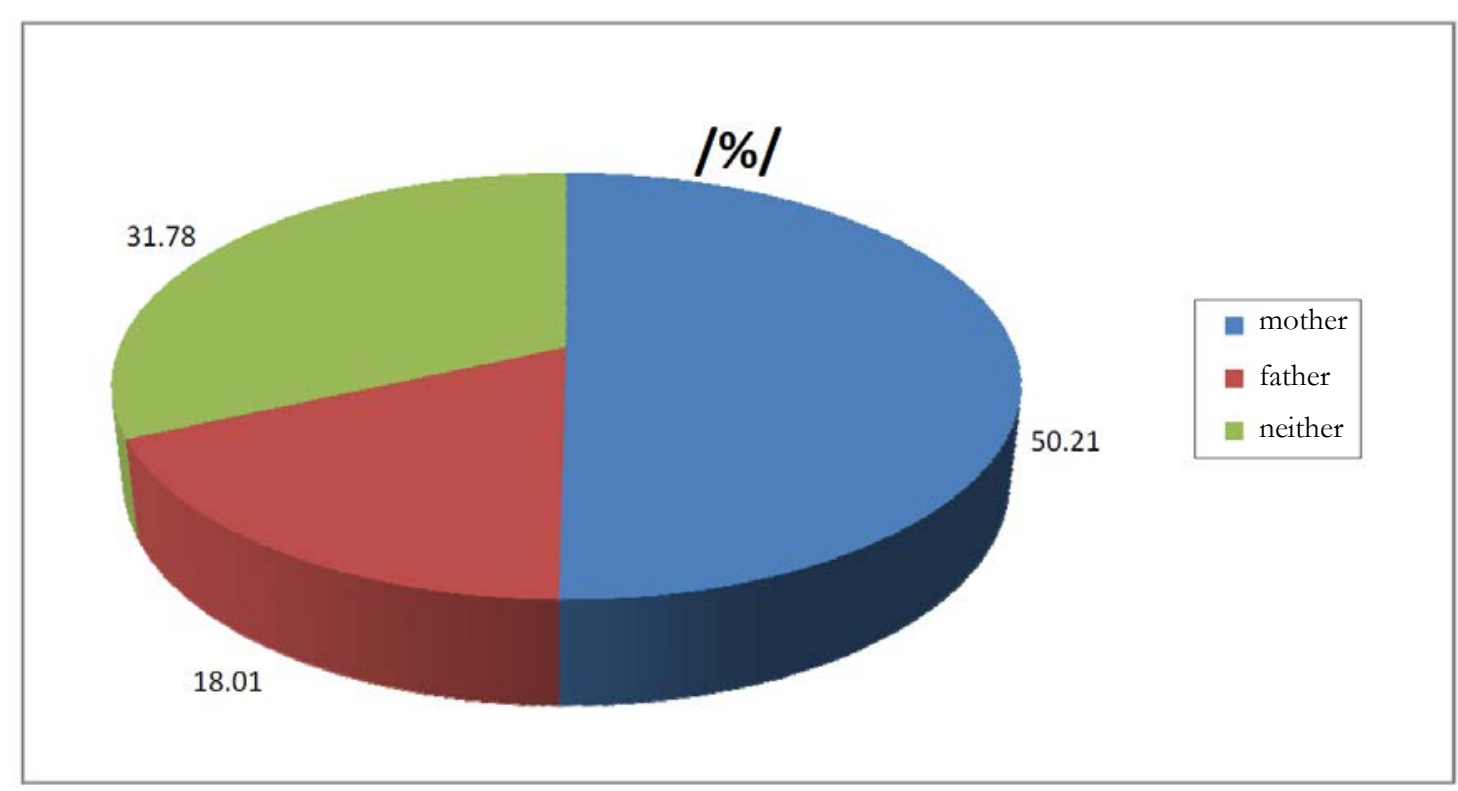


To some extent, the analysis of making the decision to give birth to a child outside marriage outlines the possible expectations related to who will look after the extramarital child after leaving the maternity ward. The study analyzed this question in particular, as well as some of the factors which predetermined the decision to raise a child born outside marriage. [2, 6]

The study established that one third of single mothers decide to put their children up for adoption.

On the other hand, the fact that a certain part of single mothers keep the children because the father recognized the child indicates the need for increasing public impact on fathers of extramarital children with view of achieving more favorable development of their relationship with the children and the mothers. This is also indicated by the established minimum number of marriages after the birth of the children.

Trying to determine the factors which influence the single mother's decision to raise her child herself, we analyzed those of them which show a connection with the financial and household living conditions after the single mother and her child leave the maternity ward, as well as some factors related to the value orientation of the single mother's personality. [3, 7]

The study took into account financial and household conditions since they are of major importance both for the mother's and the newborn's health status.

The results obtained show that after they leave the maternity ward, nearly half the single mothers (44\%) go to live with their parents. Another significant part of the studied sample (56\%) rent a place or dormitory. A small part (6\%) of the respondents did not know where they will live after leaving the maternity ward because they left their homes during the pregnancy in an attempt to hide their condition.

The responses to the question who will support the single mother financially show that $43 \%$ of the mothers are self-supporting, i.e. they are working single mothers.

However, the relative share of single mothers supported by their parents is not small (30\%). This financial dependence on her parents combined with the latter's negative attitude towards the extramarital pregnancy seems to cause serious hesitation in the single mother whether to raise the child herself or not.

It is a well-known fact that the family is one of the fundamental social values. The respondents' answers to the question about the importance of the family in life generally show the following regularities. The family is highly valued by the majority of the representatives of the two groups under comparison ( $86 \%$ of single mothers and $98 \%$ of married mothers). These results show the great importance of how high the family is ranked as a social value in decision making, but due to the relatively small number of single mothers who gave a negative answer, the factor as a whole does not have a strong impact on making the decision to raise the child. This dependency is also reflected by Cramer's correlation coefficient value $(0.80)$.

The value orientations of the mothers' personalities are not just their assessment of individual social values. What is more important is that they influence the decision making process whether to raise or put their child up for adoption. 


\section{Conclusion}

The study of the risk factors related to the family environment of single mothers is of key importance. They are directly correlated with the social aims and orientations of the family and its microclimate. And those in turn depend, to one degree or another, on the parents' attitude towards the children and the dominant role of one of the parents. Because any peculiarity in the requirements and norms towards the children and any discrepancy between the perception of them and the actual reality in the family gives rise to conflict and impacts the mental development of the young woman, the formation of her personality, and her way of life. They also explain to a significant degree the difficulties in making the decision to carry and give birth to a child outside marriage. The dependency between this factor and extramarital pregnancy is most prominent in cases where there is no parental authority and control.

\section{References}

1. Amato PR. The impact of family formation change on the cognitive, social, and emotional wellbeing of the next generation. Future of Children. 2005; 15(2): 75-96.

2. Buchanan A et al. Parental background, social disadvantage, public "care," and psychological problems in adolescence and adulthood. Journal of the American Academy of Child \& Adolescent Psychiatry. 2000; 39(11):1415-23

3. Cairney J, Wade TJ. Single parent mothers and mental health care service use. Social Psychiatry \& Psychiatric Epidemiology. 2002; 37(5):236-42.

4. Cherian VI, Malehase MC. The relationship between parental control and scholastic achievement of children from single- and two-parent families. Journal of Social Psychology. 2000; 140(5):665-7.

5. Coley RL. (In)visible men. Emerging research on low-income, unmarried, and minority fathers. American Psychologist. 2001; 56(9):743-53.

6. Compan $E$ et al. Doing things together: adolescent health and family rituals. Journal of Epidemiology \& Community Health. 2002; 56(2):89-94.

7. Curtis LJ et al. The role of permanent income and family structure in the determination of child health in Canada. Health Economics. 2001; 10(4):287-302.

8. Dickinson A. The single life. Time. 2001; 157(21):92.

9. Ellison MA. Authoritative knowledge and single women's unintentional pregnancies, abortions, adoption, and single motherhood: social stigma and structural violence. Med Anthropol Q. 2003; 17(3):322-47.

10. Stammers T. Teenage pregnancies are influenced by family structure. Bmj. 2002; 324(7328):51.

11. Teolova E. Women's health - a strategic goal in overcoming gender inequality. [Article in Bulgarien] Social medicine. 2002; 4:5-8.

12. Zeitlin JA et al. Marital status, cohabitation, and risk of preterm birth in Europe: where births outside marriage are common and uncommon. Paediatric and Perinatal Epidemiology. 2002; 16(2):124-30.

\section{Corresponding author:}

Dr. Dimitar Gugutkov, MD, PhD

Multi-profile Hospital for Active Treatment "Doverie"

1632 Sofia, district Ovcha Kupel 2, 2 Friedrich Grunanger Str.

email: d.gugutkov@mbal.doverie.bg 